\title{
Predicting a 'Combined Treatment Outcome' in Chronic Schizophrenia: The Role of Demographics, Symptomatology, Functioning and Subjective Well-being
}

Authors

Affiliations
D. Naber', S. Kollack-Walker², J. Chen², V. L. Stauffer ${ }^{3}$, B. J. Kinon ${ }^{3}$, M. Case², H. Ascher-Svanum², S. Kapur ${ }^{4}$, J. M. Kane

1 Department of Psychiatry and Psychotherapy, University of Hamburg, Hamburg, Germany

2 Lilly, USA, LLC, Indianapolis, IN, USA

${ }^{3}$ Lilly Research Laboratories, Eli Lilly and Company, Indianapolis, IN, USA

${ }^{4}$ Institute of Psychiatry, King's College of London, London, U.K.

${ }^{5}$ Zucker Hillside Hospital, Glen Oaks, NY, USA

\author{
Key words \\ - schizophrenia \\ - risperidone \\ - olanzapine \\ - antipsychotics \\ - prediction
}

\section{received $\quad 05.06 .2012$ \\ revised $\quad 09.11 .2012$ \\ accepted 13.11.2012}

Bibliography

DOI http://dx.doi.org/

$10.1055 / \mathrm{s}-0032-1331703$

Published online ahead of print: 4 January 2013

Pharmacopsychiatry 2013; 46: 114-119

(c) Georg Thieme Verlag KG

Stuttgart · New York

ISSN 0176-3679

Correspondence

D. Naber, MD

Clinic for Psychiatry and

Psychotherapy

University Hospital Hamburg-

Eppendorf

Martinistraße 52

20246 Hamburg

Germany

Tel.: +49/40/741052201

Fax: +49/40/7410 52999

naber@uke.de

S. Kollack-Walker, PhD

Lilly USA, LLC

Lilly Corporate Center, DC 4133

Indianapolis

IN 46285

USA

Tel.: + 1/317/433 4654

Fax: $+1 / 317 / 2767100$

Kollack-Walker_Sara@lilly.com

\section{Abstract}

$\nabla$

Objectives: The aim of this study was to determine what variables predict a 'combined treatment outcome' (COMBOUT) in patients with chronic schizophrenia.

Methods: This analysis $(\mathrm{n}=522)$ was based on a randomized, double-blind, flexible-dose, 12-week study that enrolled chronically-ill patients diagnosed with schizophrenia or a related disorder. COMBOUT was assessed using the PANSS for symptoms, CGI-S for overall clinical status, MADRS for depressive symptoms, QLS for functioning/QOL, and SWN-K for subjective wellbeing. Possible predictors included demographics as well as baseline scores (Model I), and early change (week 2) scores (Model II).

\begin{tabular}{ll}
\hline Abbreviations \\
AIMS & Abnormal Involuntary Movement Scale \\
CGI-S & Clinical, Global Impressions - Severity \\
COMBOUT & 'combined treatment outcome' \\
EPS & extrapyramidal symptoms \\
mg & milligram \\
MADRS & Montgomery-Asberg Depression Rat- \\
& ing Scale \\
n & number \\
PANSS & Positive and Negative Syndrome Scale \\
QLS & Quality of Life Scale \\
QOL & quality of life \\
SD & standard deviation \\
SOFAs & Scale of Occupational and Functional \\
& Assessment \\
SOFI & Schizophrenia Objective Functioning \\
SP & Instrument \\
SWN-K & Study Period \\
& Subjective Well-being on Neurolep- \\
tics Scale
\end{tabular}

Results: Model I: significantly better outcome (higher COMBOUT score) was observed in patients with lower MADRS $(\mathrm{T}=-6.36$; $\mathrm{p}<0.001)$ or higher QLS $(\mathrm{T}=5.05$; $\mathrm{p}<0.001)$ scores at baseline. Model II: significantly better COMBOUT was observed in patients with early improvement of QLS $\quad(T=4.93 ; \quad p<0.001), \quad$ SWN-K $\quad(T=3.88$; $\mathrm{p}<0.001)$, PANSS $(\mathrm{T}=-2.32 ; \mathrm{p}=0.021)$ and CGI-S scores $(\mathrm{T}=-2.22 ; \mathrm{p}=0.027)$. Changes in EPS were not predictors of COMBOUT in the models tested. Conclusion: COMBOUT at endpoint was predicted by lower depressive symptom score and higher QOL at baseline and by early improvement in psychopathology, quality of life and subjective well-being. 
results from a 3-month, observational study designed, in part, to assess the role of clinician-rated measures and subjective wellbeing at baseline as predictors of a 'combined outcome criterion' inclusive of endpoint scores on symptomatology, functioning and subjective well-being. Their findings demonstrated that, while all response categories were significantly associated with the 'combined outcome criterion', subjective well-being and social functioning demonstrated the greatest predictive value. Using related constructs but with different measurement scales and inclusion of the assessment of depressive symptoms, the objective of this study was to determine what variables predict a 'combined treatment outcome' (COMBOUT) in patients with schizophrenia. COMBOUT was defined as a combination of endpoint scores on measures of psychopathology, depressive symptoms, functioning/QOL and subjective well-being. Possible predictors included demographics, baseline and early change scores of these 5 domains as well as of extrapyramidal symptoms.

\section{Patients and Methods \\ $\nabla$}

\section{Study design}

This analysis was based on a randomized, double-blind, flexibledosed, parallel 12-week study enrolling 628 patients to explore the relationship between early response to an antipsychotic medication and subsequent improvement in psychopathology (primary outcome measure) using the oral atypical antipsychotic risperidone. The analysis focused on 522 patients who entered the third study period and were treated for up to 12 weeks (as described below). Patients met diagnostic criteria for schizophrenia, schizoaffective disorder or schizophreniform disorder according to the Diagnostic and Statistical Manual of Mental Disorders, Fourth Edition (DSM-IV). After complete description of the study was given to patients, written informed consent was obtained. In addition, the study was approved by the ethics committee from each Institution in which it was conducted. Patient confidentiality was not breached, and the study was done in accordance with the Declaration of Helsinki.

The primary manuscript from this clinical trial describes in detail the overall study design, inclusion/exclusion criteria, and concomitant medications [6]. In brief, there were 3 Study Periods (SP): SPI, screening, SPII, study enrollment in which all patients were treated with risperidone (2-6 mg/day) during the initial 2 weeks, SPIII, early responder status was assessed (response defined as achieving $\geq 20 \%$ reduction in PANSS total score), with early responders $(\mathrm{N}=144)$ continuing on risperidone (2-6 mg/day) for 10 additional weeks and early nonresponders randomized $(1: 1)$ to either stay on risperidone ( $\mathrm{N}=192$; dose range: $2-6 \mathrm{mg} / \mathrm{day})$ or switch to olanzapine ( $\mathrm{N}=186$; dose range:10-20 mg/day) for 10 additional weeks of treatment. Patients had to be at least moderately ill at the start of the study and experiencing an exacerbation of their illness within the 2 weeks preceding visit 1 that led to an intensification of the level of psychiatric care.

\section{Measures}

The Positive and Negative Syndrome Scale (PANSS) [13] was used to assess the patients' psychopathology, the Clinical Global Impressions - Severity Scale (CGI-S) [14] to assess the overall clinical severity of the disease, the Montgomery-Asberg Depression Rating Scale (MADRS) [15] to assess depressive symptoms, the Quality Of Life Scale (QLS) [16] and the Schizophrenia Objective Functioning Index (SOFI) [17] to assess overall functioning, and the Subjective Well-Being On Neuroleptics - Short Form Scale (SWN-K) [18] to assess subjective well-being.

In addition, the Simpson-Angus Scale [19] was used to assess parkinsonian symptoms, the Barnes Akathisia Scale [20] to assess akathisia, and the Abnormal Involuntary Movement Scale (AIMS) [14] to assess tardive dyskinesia.

\section{The 'combined outcome criterion'}

COMBOUT at week 12 included PANSS total, CGI-S, MADRS total, QLS total and SWN-K total scores. The PANSS and CGI-S were measured at every visit. MADRS, QLS and SWN-K were measured at visit 1 (baseline), 4 (week 2), 7 (week 6), and 9 (week 12). For each scale, the last non-missing observation in study period III (visits 5-9) was used to calculate COMBOUT. Each scale was transformed, and as necessary reversed, into measures ranging from 0-100 according to the methodology in [21], with higher scores reflecting a better outcome. COMBOUT is the summation of those equally weighted 5 transformed measures, with a range from $0-500$. If one of the 5 transformed measures was missing, then COMBOUT was treated as missing.

\section{Statistical methodology}

Baseline demographic characteristics and disease state were summarized as mean \pm standard deviation (SD) for continuous variables, and number of counts and percentages for categorical variables. The non-parametric sign tests were applied to test mean changes in PANSS, CGI-S, QLS, MADRS, and SWN-K from baseline to week 2 and endpoint at week 12. 2 linear regression models were adopted to predict the COMBOUT at week 12. In the first model, we investigated whether baseline scores of PANSS, CGI-S, MADRS, QLS, and SWN-K are predictors of COMBOUT. In the second model, we studied whether the early changes in those 5 scales from baseline to week 2 can be predictive of COMBOUT. A 2-tailed $\alpha$ level of 0.05 was applied to all the hypothesis tests. All analyses were performed using statistical software (SAS Drug Development; SAS Institute Inc, Cary, NC).

\section{Results \\ $\nabla$}

\section{Patients' characteristics}

- Table 1 summarizes the demographics and disease state of the 522 patients at baseline. Patients were predominantly male $(61.7 \%)$ with an average age of 41.9 years. There was an equal distribution of patients who were Caucasian (44.8\%) and those who were of African descent (44.8\%).

\section{Dosing}

The overall mean dose (from visit 5 to 9) was $4.78 \mathrm{mg} /$ day for the early-responders treated with risperidone, $5.04 \mathrm{mg} /$ day for the early non-responders treated with risperidone, and $17.26 \mathrm{mg} /$ day for the early non-responders who were treated with risperidone for the first 2 weeks and then switched to olanzapine.

\section{Changes observed in individual measures}

At endpoint (week 12), 87\% ( $n=456)$ of patients had non-missing values of COMBOUT with a mean of 338.4 (SD 54.7, range 156.1-477.5). The normality test indicated that COMBOUT was normally distributed. For mean changes from baseline to week 2 , 
Table 1 Baseline characteristics.

\begin{tabular}{|lc|}
\hline & HGMN (n=522) \\
\hline Gender (female; $\mathrm{n}, \%)$ & $200(38.3)$ \\
\hline Age (mean, SD) & $41.9(11.0)$ \\
\hline Race (n, \%) & $234(44.8)$ \\
\hline Caucasian & $234(44.8)$ \\
\hline African descent & $54(10.4)$ \\
\hline other & $92.0(13.6)$ \\
\hline PANSS total (mean, SD) & $31.9(5.2)$ \\
\hline PANSS positive score (mean, SD) & $22.0(5.6)$ \\
\hline PANSS negative score (mean, SD) & $4.6(0.6)$ \\
\hline CGI-S (mean, SD) & $16.3(9.1)$ \\
\hline MADRS total (mean, SD) & $51.1(21.2)$ \\
\hline QLS total (mean, SD) & $76.7(17.0)$ \\
\hline SWN-K total (mean, SD) & $56.1(16.9)$ \\
\hline SOFI total (mean, SD) & $0.6(1.73)$ \\
\hline AIMS baseline total (items 1-7) (mean, SD) & $0.2(0.60)$ \\
\hline The Barnes Akathisia Baseline Global Score (mean, SD) & $1.2(2.76)$ \\
\hline The Modified Simpson-Angus Baseline Total (mean, SD) & \\
\hline *PANSS positive and negative factors as identified by Marder et al. [36] \\
\hline AIMS, Abnormal Involuntary Movement Scale; CGI-S, Clinical, Global Impressions- \\
\hline Severity; MADRS, Montgomery-Asberg Depression Rating Scale; n, number; PANSS, \\
\hline Positive and Negative Syndrome Scale; QLS, Quality of Life scale; SD, standard \\
\hline deviation; SOFI, Schizophrenia Objective Functioning Instrument; SWN-K, Subjective \\
\hline Well-being on Neuroleptics scale
\end{tabular}

Table 2 Mean changes from baseline to week 2 and week 12 .

\begin{tabular}{|c|c|c|c|}
\hline Scales & $\mathbf{n}$ & Mean Changes & p-value \\
\hline \multicolumn{4}{|l|}{ From baseline to week 2} \\
\hline PANSS total & 521 & -13.73 & $<0.001$ \\
\hline PANSS positive score* & 522 & -5.34 & $<0.001$ \\
\hline PANSS negative score* & 521 & -2.76 & $<0.001$ \\
\hline CGI-S & 522 & -0.65 & $<0.001$ \\
\hline MADRS total & 521 & -4.91 & $<0.001$ \\
\hline QLS total & 499 & 5.01 & $<0.001$ \\
\hline SWN-K total & 475 & 6.44 & $<0.001$ \\
\hline \multicolumn{4}{|l|}{ From baseline to week 12} \\
\hline PANSS total & 506 & -23.43 & $<0.001$ \\
\hline PANSS positive score* & 507 & -9.62 & $<0.001$ \\
\hline PANSS negative score* & 506 & -4.34 & $<0.001$ \\
\hline CGI-S & 506 & -1.19 & $<0.001$ \\
\hline MADRS total & 478 & -6.07 & $<0.001$ \\
\hline QLS total & 457 & 10.73 & $<0.001$ \\
\hline SWN-K total & 452 & 9.94 & $<0.001$ \\
\hline \multicolumn{4}{|c|}{ *PANSS positive and negative factors as identified by Marder et al. [36] } \\
\hline \multicolumn{4}{|c|}{$\begin{array}{l}\text { AIMS, Abnormal Involuntary Movement Scale; CGI-S, Clinical, Global Impressions- } \\
\text { Severity; MADRS, Montgomery-Asberg Depression Rating Scale; n, number; p-value, } \\
\text { p-values of the sign test; PANSS, Positive and Negative Syndrome Scale; QLS, Quality } \\
\text { of Life scale; SD, standard deviation; SOFI, Schizophrenia Objective Functioning }\end{array}$} \\
\hline
\end{tabular}

and from baseline to week 12 , the sign test showed highly significant changes across all scales measured ( $\bullet$ Table 2 ).

\section{Relationships between outcome domains}

The Pearson's correlation coefficients among all measures at baseline and at week 2 are shown in $\odot$ Table 3 . All correlations were significant. The highest correlation coefficients were observed between the QLS and SOFI (at baseline, $r=0.662$, $\mathrm{p}<0.001$; at week 2, r $=0.732, \mathrm{p}<0.001$ ), indicating that the QLS and SOFI are highly correlated and likely measuring similar constructs. As a consequence, the QLS was used as a measure in calculating and predicting COMBOUT.
Other comparisons at baseline revealed moderate correlations between the PANSS total score and scores for the CGI-S $(r=0.447$; $\mathrm{p}<0.001)$, QLS $(\mathrm{r}=-0.391 ; \mathrm{p}<0.001)$ and SOFI $(\mathrm{r}=-0.417$; $\mathrm{p}<0.001$ ). Correlations between the PANSS total score and scores on the MADRS $(r=0.271 ; p<0.001)$ and SWN-K $(r=-0.193$; $\mathrm{p}<0.001$ ) were substantially lower. Interestingly, the highest correlation coefficient observed for the MADRS was the SWN-K $(r=-0.390 ; p<0.001)$ and similarly, the highest correlation coefficient observed for the SWN-K was the MADRS $(r=-0.496$; $p<0.001$ ). In general, the correlation coefficients were larger at week 2 , with the exception of the correlation coefficient observed between the PANSS total and SOFI which was slightly smaller at week 2 compared to baseline.

\section{Predicting COMBOUT at 3 months}

We adopted 2 linear regression analyses (models) to predict COMBOUT at endpoint ( $\bullet$ Table 4 ). In each model, age, race, sex, and 3 EPS measures were included in addition to the 5 scales of interest: PANSS, MADRS, QLS, CGI-S and SWN-K. Pooled investigator was also included as a blocking variable to account for site variations. Model I included only baseline variables, whereas Model II included early change variables at week 2 and was controlled for baseline efficacy and EPS measures. The models incorporated the same COMBOUT at endpoint.

Model I (total scores at baseline): Out of 522 patients, $82 \%$ $(n=428)$ had complete data. No significant differences in baseline characteristics were observed between the 428 subjects included in Model 1 and the 94 subjects who did not enter the model due to missing values on certain variables. The results revealed that patients having lower baseline MADRS scores $(\mathrm{T}=-6.36 ; \mathrm{p}<0.001)$ and those with higher baseline QLS scores $(\mathrm{T}=5.05 ; \mathrm{p}<0.001)$ had significantly higher COMBOUT scores at week 12 . For the QLS, a separate analysis incorporating its 4 subscale scores revealed that patients with higher QLS interpersonal relations $(p<0.001)$ and instrumental role $(p=0.022)$ subscale scores had significantly greater COMBOUT scores at endpoint. Race (ethnicity) was not a significant predictor of COMBOUT $(p=0.052)$. However, a breakdown analysis showed that Caucasians had significantly higher $(p=0.008)$ COMBOUT scores at week 12 than African Americans. All other variables were not found to be predictive of COMBOUT in Model I. The R-square was 0.287 . The model diagnostic showed that both the normality and constant-variance assumptions were met.

Model II (mean change at week 2 using total scores; controlled for baseline): Out of the 522 patients, $76 \%(n=398)$ had complete data. The 398 subjects included in Model II had a significantly higher SWN-K total score at baseline $(\mathrm{p}=0.032)$ than the 124 subjects who did not enter the model. No other differences in baseline characteristics were observed between these 2 groups. The results showed that an early reduction in the PANSS total score $(\mathrm{T}=-2.32 ; \mathrm{p}=0.021)$ or CGI-S score $(\mathrm{T}=-2.22$; $\mathrm{p}=0.027)$, or an early increase in the QLS score $(\mathrm{T}=4.93$; $\mathrm{p}<0.001)$ or SWN-K score $(\mathrm{T}=3.88 ; \mathrm{p}<0.001)$ led to a significantly higher COMBOUT at endpoint. The early change in MADRS did not predict COMBOUT. Using PANSS factor scores for positive and negative symptoms, we found that early change in the PANSS positive factor score $(\mathrm{p}=0.047)$, but not the PANSS negative factor score, was significantly associated with COMBOUT. All other variables were not found to be predictive of COMBOUT in Model II. The R-square was 0.546 . The model diagnostic showed 
Table 3 Pearson's correlation coefficients among all measures at baseline and week 2 .

\begin{tabular}{|c|c|c|c|c|c|c|}
\hline & PANSS Total & CGI-S & MADRS & SWN-K & QLS & SOFI \\
\hline PANSS total & - & 0.637 & 0.475 & -0.260 & -0.518 & -0.444 \\
\hline CGI-S & 0.447 & - & 0.370 & -0.243 & -0.503 & -0.473 \\
\hline MADRS & 0.271 & 0.147 & - & -0.496 & -0.336 & -0.296 \\
\hline SWN-K & -0.193 & -0.145 & -0.390 & - & 0.331 & 0.283 \\
\hline QLS & -0.391 & -0.252 & -0.179 & 0.209 & - & 0.732 \\
\hline SOFI & -0.417 & -0.323 & -0.142 & 0.153 & 0.662 & - \\
\hline
\end{tabular}

The numbers below the diagonal are correlations present at baseline. The numbers above the diagonal (shaded cells) are correlations shown at week 2 All correlations were significant

AIMS, Abnormal Involuntary Movement Scale; CGI-S, Clinical, Global Impressions-Severity; MADRS, Montgomery-Asberg Depression Rating Scale; $n$, number; PANSS, Positive and Negative Syndrome Scale; QLS, Quality of Life scale; SD, standard deviation; SOFI, Schizophrenia Objective Functioning Instrument; SWN-K, Subjective Well-being on Neuroleptics scale

\begin{tabular}{|c|c|c|c|c|c|c|}
\hline Models & Beta & $\mathbf{T}$ & Lower $95 \%$ Cl & Upper $95 \%$ Cl & p-value & \multirow{29}{*}{ Models I and II. } \\
\hline \multicolumn{6}{|c|}{ I. Predicting COMBOUT using baseline scores $(n=428)$} & \\
\hline Age (in years) & 0.21 & 0.91 & -0.25 & 0.68 & 0.362 & \\
\hline Race & - & - & - & - & 0.052 & \\
\hline Sex & 0.31 & 0.06 & -9.9 & 10.53 & 0.952 & \\
\hline PANSS total & -0.10 & -0.42 & -0.56 & 0.37 & 0.677 & \\
\hline MADRS total & -2.11 & -6.36 & -2.76 & -1.45 & $<0.001$ & \\
\hline QLS total & 0.69 & 5.05 & 0.42 & 0.96 & $<0.001$ & \\
\hline CGI-S & -1.19 & -0.26 & -10.23 & 7.85 & 0.795 & \\
\hline SWN-K total & -0.03 & -0.17 & -0.34 & 0.29 & 0.867 & \\
\hline AIMS total (items $1-7$ ) & -0.52 & -0.32 & -3.71 & 2.67 & 0.748 & \\
\hline Barnes Akathisia Global Score & 3.38 & 0.65 & -6.92 & 13.68 & 0.519 & \\
\hline Modified Simpson-Angus total & -0.28 & -0.22 & -2.73 & 2.17 & 0.823 & \\
\hline \multicolumn{6}{|c|}{ II. Predicting COMBOUT using score changes from baseline $(n=398)$} & \\
\hline Age (in years) & 0 & -0.02 & -0.40 & 0.39 & 0.981 & \\
\hline Race & - & - & - & - & 0.917 & \\
\hline Sex & 1.47 & 0.33 & -7.21 & 10.16 & 0.739 & \\
\hline PANSS total changes & -0.52 & -2.32 & -0.96 & -0.08 & 0.021 & \\
\hline MADRS total changes & -0.11 & -0.26 & -0.92 & 0.71 & 0.797 & \\
\hline QLS total changes & 0.83 & 4.93 & 0.50 & 1.17 & $<0.001$ & \\
\hline CGI-S changes & -8.84 & -2.22 & -16.70 & -1.01 & 0.027 & \\
\hline SWN-K total changes & 0.70 & 3.88 & 0.35 & 1.06 & $<0.001$ & \\
\hline AIMS total (items 1-7) changes & -2.71 & -1.52 & -6.22 & 0.80 & 0.130 & \\
\hline Barnes Akathisia Global score changes & 5.17 & 1.25 & -2.95 & 13.30 & 0.211 & \\
\hline Modified Simpson-Angus total changes & 0.29 & 0.22 & -2.29 & 2.86 & 0.828 & \\
\hline \multicolumn{6}{|l|}{$\mathrm{n}:$ the number of subjects used in each model } & \\
\hline \multicolumn{6}{|l|}{ Dashes indicate that the data was not available } & \\
\hline \multicolumn{6}{|c|}{ AIMS, Abnormal Involuntary Movement Scale; CGI-S, Clinical, Global Impressions-Severity; MADRS, Montgomery-Asberg Depression } & \\
\hline \multicolumn{6}{|c|}{$\begin{array}{l}\text { Rating Scale; n, number; PANSS, Positive and Negative Syndrome Scale; QLS, Quality of Life scale; SD, standard deviation; SOFI, Schizo- } \\
\text { phrenia Objective Functioning Instrument; SWN-K, Subjective Well-being on Neuroleptics scale }\end{array}$} & \\
\hline
\end{tabular}

that both the normality and constant-variance assumptions were met.

\section{Discussion}

In this study, we investigated the predictive power of several domains (baseline and improvement at week 2) on 12 week 'combined treatment outcome' (COMBOUT) in patients with schizophrenia. Possible predictors included demographics, baseline scores and early change scores for psychopathology, functioning/quality of life, subjective well-being, and extrapyramidal symptoms. In the first regression analysis (Model I), which focused on baseline variables, СОМBOUT was predicted by a lower level of depressive symptoms, and better expert-rated quality of life (social and occupational functioning). In the second regression analysis (Model II), which focused on early change, COMBOUT was predicted mostly by increases in QLS and
SWN-K, followed by decreases in PANSS and CGI-S at week 2. EPS variables were not predictors of COMBOUT in either model tested.

A number of reports in the literature have highlighted global measures of mental, occupational, and psychosocial functioning (e.g., Global Assessment of Functioning, useful work/QLS instrumental role domain, Medical Outcomes Study-Short Form 36-Item Health Survey) at the start of a study as predictors of subsequent treatment outcomes [22-24]. The current findings with the QLS total score, and specifically with the interpersonal and instrumental (occupational) domains, are consistent with these prior findings.

Similarly, we also observed lower baseline depressive symptoms to be predictive of a better 'combined treatment outcome'. These results agree with previous research, patients with more severe depressive symptoms have been reported to have worse treatment outcomes $[25,26]$, although some studies have suggested otherwise $[23,27,28]$. The discrepancy might be explained by a 
number of factors, influencing the occurrence and course of depressive symptoms in schizophrenia (such as patient's age, severity of positive, negative and cognitive symptoms, patient population, particularly acute vs. stable, institutionalized vs. non-institutionalized) [28]. Numerous long-term studies have indicated that of the different psychopathological domains, higher depressive symptoms are most strongly associated with lower QOL [29-32], and lower subjective well-being [33,34] in patients with schizophrenia.

Lambert et al. [12] had previously reported negative symptoms and CGI-S scores at baseline as predictive of a combined treatment outcome at 3 months. We did not find the PANSS total or CGI-S scores at baseline to be predictive of COMBOUT. Given that the PANSS total score was not predictive of COMBOUT, we conducted additional analyses on the PANSS positive or negative factor scores, which were also not predictive of COMBOUT (data not shown). Differences between the 2 studies may underlie these disparate findings, including that patients in the Lambert et al. study were all diagnosed with schizophrenia, had higher baseline CGI-S scores and lower SWN-K scores, used amisulpiride as the antipsychotic agent, and reported somewhat different measures for the PANSS.

Early change at week 2 across a broad array of outcome domains - symptoms (PANSS total score, CGI-S), functioning/quality of life (QLS) and subjective well-being (SWN-K) - was predictive of COMBOUT. This finding was consistent with data reported by Lambert et al. [12] demonstrating that patients who achieved a pre-defined level of response across measures of symptoms (PANSS positive and negative scores, CGI-S), functioning (Scale of Occupational and Functional Assessment, SOFAs) and subjective well-being $(S W N-K)$ at 4 weeks were predictive of a combined treatment outcome. Also consistent with Lambert et al. [12], we found that early change in functioning and subjective well-being showed the strongest relationship in predicting COMBOUT in comparison to symptom severity. This finding is also consistent with the de Haan et al. study [34] in which early improvement among first episode patients in subjective well-being, but not early improvement in PANSS, has been associated with enduring symptom remission [35]. These collective findings highlight the potential value of assessing early improvement in functioning and subjective well-being as potential prognostic indicators of a patient's ultimate treatment response.

Surprisingly, while inclusion of the MADRS revealed a significant relationship between depressive symptoms at baseline and COMBOUT at endpoint, a similar relationship was not observed between COMBOUT and early change in the MADRS at week 2 . Previous findings (from this dataset) revealed early improvement in MADRS scores during the initial 2 weeks of drug therapy [11]. These earlier findings, though, were based only on those patients treated with risperidone for the entire 12 weeks. A separate group of patients (early non-responders to risperidone who were switched to olanzapine after 2 weeks), were excluded from that analysis. These patients were included in the current study. Of interest, these patients had shown significantly greater improvement in the MADRS compared to early non-responders maintained on risperidone [6] and slightly different results in model II.

We did not find either baseline scores or early change scores in EPS measures of akathisia (Barnes Akathisia Scale), parkinsonism (Simpson-Angus Scale), or tardive dyskinesia (AIMS) to be predictive of COMBOUT. However, further study is needed to assess change in EPS status using categorical scores (and not only mean scores) across these measures. Another approach one that incorporates EPS measures scores into a single "Movement Disorder Index" - should be considered. A recent post-hoc analysis of a 1-year study of patients with schizophrenia [37] found that patients who experienced worsening of the Movement Disorder Index (which is based on the Barnes Akathisia Scale, the Simpson-Angus Scale and the AIMS, and use of antiparkinsonian agents) have evidenced significantly poorer clinical and functional outcomes.

\section{Limitations}

$\nabla$

Equal weighting was used for the 5 outcome measures of interest - PANSS, CGI-S, MADRS, QLS and SWN-K. This approach seemed to be justified since there are no data indicating that another method would be more appropriate.

Switching a subset of patients from risperidone to olanzapine (as prescribed in the study design) may have confounded to some degree the prediction of COMBOUT.

The potential value of using a 'combined treatment outcome' incorporating multiple endpoints as an approach to assess a multifaceted treatment outcome relevant to each patient's response and potential for recovery is worth further study.

\section{Conclusions}

$\nabla$

A broad multidimensional outcome measure, which incorporates psychopathology, functioning/quality of life and subjective well-being following 12 weeks of therapy, was predicted by a few baseline characteristics and by greater early improvement in most domains, particularly by early change in functioning/QOL and subjective well-being. Not focusing only on changes of (positive) psychopathology, but to include broader early clinical indicators may assist in identifying patients who require targeted interventions to help optimize their treatment outcomes. These findings also lend further support to the value of the early response paradigm, which can be extended to most outcome measures.

\section{Role of Funding Source}

$\nabla$

This study was funded by Eli Lilly and Company.

\section{Contributors}

$\nabla$

JC and MC contributed to the design of the study, and performed the statistical analysis. DN, SKW, VLS conceived the study, and DN, SKW, VLS, HAS and BJK contributed to its design and coordination. SKW wrote the initial draft of the manuscript, and coordinated the development of the final draft. All authors including DN, SKW, VLS, HAS, BJK, JC, MC, JMK, and SK participated in the analysis and interpretation of the data, and in drafting and/or revising the manuscript critically for important intellectual content. In addition, all authors read and approved the final version of the manuscript. 


\section{Acknowledgements}

We would like to thank Heather Fox for coordinating the editing and formatting of this manuscript. We would also like to acknowledge the editorial assistance provided from PRIMO Scientific Corporation in editing and formatting this manuscript per journal requirements.

\section{Conflict of Interest}

Yes: Drs. Kinon, Chen, Case, Ascher-Svanum, Stauffer, KollackWalker, are employees of Eli Lilly and Company. Dr. Kane serves as a Consultant and on Advisory Boards for Bristol-Myers Squibb, Otsuka, Eli Lilly and Company, Janssen, Johnson \& Johnson, PRD, MDS Pharma Services, Pfizer, Inc., Solvay Pharmaceuticals, Inc., Wyeth Pharmaceutical, Lundbeck, Vanda Pharmaceutical, and Astra-Zeneca. In addition, Dr. Kane serves on speakers bureaus for Bristol-Myers Squibb, and Janssen. Dr. Shitij Kapur has had affiliations with the following commercial organizations over the last 5 years: AstraZeneca, Bristol Meyers Squibb, Eli Lilly and Company, EMD Pharmaceuticals, Inc., Darmstadt, GlaxoSmithKline, Janssen, Neuromolecular Pharmaceuticals, Otsuka America Pharmaceutical, Inc., Organon Pharmaceuticals USA, Pfizer, Sanofi-Synthelabo, Servier, and Solvay Wyeth. Funding of this study was provided by Eli Lilly and Company. Dr. Naber received honoraria and/or acted as consultant for AstraZeneca, Bristol-Myers Squibb, Eli Lilly, JanssenCilag, Pfizer, Schering-Plough, Servier and Wyeth.

\section{References}

1 Agid O, Kapur S, Arenovich T, Zipursky RB. Delayed-onset hypothesis of antipsychotic action: a hypothesis tested and rejected. Arch Gen Psychiatry 2003; 60: 1228-1235

2 Leucht S, Busch R, Hamann J, Kissling W, Kane JM. Early-onset hypothesis of antipsychotic drug action: a hypothesis tested, confirmed and extended. Biol Psychiatry 2005; 57: 1543-1549

3 Ascher-Svanum H, Nyhuis AW, Faries DE, Kinon BJ, Baker RW, Shekhar A. Clinical, functional and economic ramifications of early nonresponse to antipsychotics in the naturalistic treatment of schizophrenia. Schizophr Bull 2008; 34: 1163-1171

4 Correll CU, Malhotra AK, Kaushik S, McMeniman M, Kane JM. Early prediction of antipsychotic response in schizophrenia. Am J Psychiatry 2003; 160: 2063-2065

5 Kinon BJ, Chen L, Ascher-Svanum H, Stauffer VL, Kollack-Walker S, Sniadecki JL, Kane JM. Predicting response to atypical antipsychotics based on early response in the treatment of schizophrenia. Schizophr Res 2008; 102: 230-240

6 Kinon BJ, Chen L, Ascher-Svanum H, Stauffer VL, Kollack-Walker S, Zhou $W$, Kapur $S$, Kane JM. Early response to antipsychotic drug therapy as a clinical marker of subsequent response in the treatment of schizophrenia. Neuropsychopharmacology 2010; 35: 581-590

7 Leucht S, Busch R, Kissling W, Kane JM. Early prediction of antipsychotic nonresponse among patients with schizophrenia. J Clin Psychiatry 2007; 68: 352-360

8 Leucht S, Shamsi SA, Busch R, Kissling W, Kane JM. Predicting antipsychotic drug response - replication and extension to six weeks in an international olanzapine study. Schizophr Res 2008; 101: 312-319

9 Warner R. Recovery from schizophrenia and the recovery model. Curr Opin Psychiatry 2009; 22: 374-380

10 Naber D. Subjective effects of antipsychotic treatment. Acta Psychiatr Scand 2005; 111: 81-83

11 Kinon BJ, Chen L, Ascher-Svanum H, Stauffer VL, Kollack-Walker S, Zhou W, Kapur S, Kane JM, Naber D. Challenging the assumption that improvement in functional outcomes is delayed relative to improvement in symptoms in the treatment of schizophrenia. Schizophr Res 2010; 118: 176-182

12 Lambert M, Schimmelmann BG, Naber D, Elch F-X, Schulz H, Huber CG, Karow A. Early and delayed antipsychotic response and prediction of outcome in 528 severely impaired patients with schizophrenia treated with amisulpride. Pharmacopsychiatry 2009; 42: 277-283
13 Kay SR, Fiszbein A, Opler LA. The positive and negative syndrome scale (PANSS) for schizophrenia. Schizophr Bull 1987; 13: 261-276

14 Guy W. ECDEU Assessment Manual for Psychopharmacology, Revised (Publication ADM 76-338). US Dept of Health, Education, and Welfare; Rockville, MD: 1976; 218-222

15 Montgomery SA, Asberg M. A new depression scale designed to be sensitive to change. Br J Psychiatry 1979; 134: 382-389

16 Heinrichs DW, Hanlon TE, Carpenter WT Jr. The Quality of Life Scale: an instrument for rating the schizophrenic deficit syndrome. Schizophr Bull 1984; 10: 388-398

17 Kleinman L, Lieberman J, Dube S, Mohs R, Zhao Y, Kinon B, Carpenter W, Harvey PD, Green MF, Keefe RS, Frank L, Bowman L, Revicki DA. Development and psychometric performance of the schizophrenia objective functioning instrument: an interviewer administered measure of function. Schizophr Res 2009; 107: 275-285

18 Naber D, Moritz S, Lambert M, Pajonk F, Holzbach R, Mass R, Andresen B. Improvement of schizophrenic patients' subjective well-being under atypical antipsychotic drugs. Schizophr Res 2001; 50: 79-88

19 Simpson GM, Angus JW. A rating scale for extrapyramidal side effects. Acta Psychiatr Scand Suppl 1970; 212: 11-19

20 Barnes TR. A rating scale for drug-induced akathisia. Br J Psychiatry 1989; 154: 672-676

21 Aiken LR. Formulas for equating ratings on different scales. Educational and Psychological Measurement 1987; 47: 51-54

22 Flyckt L, Mattsson M, Edman G, Carlsson R, Cullberg J. Predicting 5-year outcome in first-episode psychosis: construction of a prognostic rating scale. J Clin Psychiatry 2006; 67: 916-924

23 Lipkovich IA, Deberdt W, Csernansky JG, Buckley P, Peuskens J, KollackWalker S, Rotelli M, Houston JP. Defining "good" and "poor" outcomes in patients with schizophrenia or schizoaffective disorder: A multidimensional data-driven approach. Psychiatry Res 2009; 170: 161-167

24 Schennach-Wolff R, Jäger M, Obermeier M, Schmauss M, Laux G, Pfeiffer $H$, Naber D, Schmidt LG, Gaebel W, Klosterkötter J, Heuser I, Kühn KU, Lemke MR, Rüther E, Klingberg S, Gastpar M, Seemüller F, Möller HJ, Riedel $M$. Quality of life and subjective well-being in schizophrenia and schizophrenia spectrum disorders: valid predictors of symptomatic response and remission? World J Biol Psychiatry 2010; 11: 729-738

25 Conley RR. The burden of depressive symptoms in people with schizophrenia. Psychiatr Clin North Am 2009; 32: 853-861

26 Jin H, Zisook S, Palmer BW, Patterson TL, Heaton RK, Jeste DV. Association of depressive symptoms with worse functioning in schizophrenia: a study in older outpatients. J Clin Psychiatry 2001; 62: 797-803

27 Emsley RA, Oosthuizen PP, Joubert AF, Roberts MC, Stein DJ. Depressive and anxiety symptoms in patients with schizophrenia and schizophreniform disorder. J Clin Psychiatry 1999; 60: 747-751

28 Rieckmann N, Reichenberg A, Bowie CR, Parrella M, White L, Friedman JI, Harvey PD. Depressed mood and its functional correlates in institutionalized schizophrenia patients. Schizophr Res 2005; 77: 179-187

29 Hansson L. Determinants of quality of life in people with severe mental illness. Acta Psychiatr Scand Suppl 2006; 429: 46-50

30 Huppert JD, Weiss KA, Lim R, Pratt S, Smith TE. Quality of life in schizophrenia: contributions of anxiety and depression. Schizophr Res 2001; 51: 171-180

31 Narvaez JM, Twamley EW, McKibbin CL, Heaton RK, Patterson TL. Subjective and objective quality of life in schizophrenia. Schizophr Res 2008; 98: 201-208

32 Sim K, Mahendran R, Siris SG, Heckers S, Chong SA. Subjective quality of life in first episode schizophrenia spectrum disorders with comorbid depression. Psychiatry Res 2004; 129: 141-147

33 Karow A, Moritz S, Lambert M, Schoder S, Krausz M. PANSS syndromes and quality of life in schizophrenia. Psychopathology 2005; 38: $320-326$

$34 \mathrm{Kim} \mathrm{J}-\mathrm{H}$, Ann J-H, Kim M-J. The relationship between depressive symptoms and subjective well-being in newly admitted patients with schizophrenia. Compr Psychiatry 2010; 51: 165-170

35 de Haan L, Nimwegen L, Amelsvoort T, Dingemans P, Linszen D. Improvement of subjective well-being and enduring symptomatic remission, a 5 -year follow-up of first episode schizophrenia. Pharmacopsychiatry 2008; 41: 125-128

36 Marder SR, Davis JM, Chouinard G. The effects of risperidone on the five dimensions of schizophrenia derived by factor analysis: combined results of the North American trials. J Clin Psychiatry 1997; 58: 538-546

37 Chen L, Ascher-Svanum H, Lawson A, Stauffer V, Nyhuis A, Haynes VS, Schuh K, Kinon BJ. Movement disorders trajectories and treatment outcomes in a 1-year study of patients with schizophrenia. ACNP 2011 